\title{
REPAIR OF EXCISIONAL WOUNDS IN THE EMBRYO
}

\author{
PAUL MARTIN $^{1}$, CATHERINE NOBES ${ }^{2}$, JANE McCLUSKEY ${ }^{1}$ and JULIAN LEWIS \\ London and $O x f o r d$
}

\begin{abstract}
SUMMARY
Wound healing in the embryo, just as in the adult, comprises two tissue movements: re-epithelialisation and connective-tissue contraction. In this brief review we describe our recent studies of these two movements in both chick and rodent embryo model systems. In the chick we have evidence that the embryonic wound epidermis is drawn forwards by contraction of an actin pursestring extending around the circumference of the wound, rather than by lamellipodial crawling as in adult healing. Significant connective-tissue contraction also occurs. In the rat and mouse embryo we have examined expression of transcription factors and growth factors at the wound edge. We discuss our observations that the immediateearly gene c-fos and the growth factor transforming growth factor beta-1 are rapidly induced at the embryonic wound margin, and the possibility that these signals may trigger proliferation of wound edge cells and contraction of the exposed wound mesenchyme.
\end{abstract}

Developmental biologists have long marvelled at the healing abilities of embryos. Within 12 hours or so after a relatively major operation on a tadpole or a chick or mouse embryo, the wound will have healed over, often leaving no sign of where incisions had been made. ${ }^{1-6}$ The question of how embryos perform this highly efficient repair, and in particular how the process differs from the less perfect repair process in the adult, has attracted increasing attention in recent years. An understanding of the differences between embryonic and adult tissue repair may suggest therapeutic strategies to overcome two contrasting but equally serious problems of adult healing: that of impaired healing (under-healing) suffered, for example, by diabetics and that of hypertrophic and keloid scarring (over-healing).

It is also likely that analysis of the control of the tissue

From: 'Departments of Anatomy \& Developmental Biology and Plastic Surgery, and ${ }^{2}$ MRC Laboratory for Molecular Cell Biology, University College London; ${ }^{3}$ ICRF Developmental Biology Unit, Zoology Department, University of Oxford, UK.

Correspondence to: Paul Martin, Department of Anatomy, University College London, Gower Street, London WC1E 6BT, UK. movements of embryonic wound healing may shed light on the control of the morphogenetic tissue movements of embryogenesis such as gastrulation and neurulation. The wound healing system has the advantage that the movements are triggered at a well-defined time and place that the experimenter selects.

We have investigated wound closure in two modelsystems, the chick and rodent embryos, both of them at limb-bud stages of development when the skin is a very simple, as yet undifferentiated, structure. The chick embryo is convenient for microsurgery in ovo, while mouse and rat embryos, when removed from the uterus and grown in a small volume of medium in a roller culture bottle, allow biochemical manipulation of the wound healing environment by addition of factors to the medium bathing the wound. The mouse has advantages also for molecular genetic analysis.

We have used the chick to study the basic ground rules and cellular mechanics of embryonic wound healing: its timecourse, the relative contributions of mesenchymal contraction and epidermal movement, and the way in which the cut epidermal edge sweeps forward. In the rodent systems we have begun to investigate induction of immediate-early transcription factors and growth factors and the possibility that these molecules might provide signals for the movements of wound closure.

\section{EXPERIMENTAL DATA}

\section{Embryonic Wounds Heal in Less than a Day}

The standard excisional lesion we make on the dorsal surface of the stage 23 (Hamburger and Hamilton ${ }^{7}$ ) chick wing bud involves dissecting away a square of skin approximately $0.5 \mathrm{~mm} \times 0.5 \mathrm{~mm}$ (Fig. 1A). At this stage of development the embryonic skin consists of a bilayered epidermis - a superficial pavement-like peridermal layer overlying a basal cuboidal layer - beneath which is a rather loose homogeneous mesenchyme, not yet differentiated into dermis. Such excisional lesions close rapidly; by 6 hours the area of exposed mesenchyme is significantly reduced (Fig. 1B, C) and most wounds are healed 


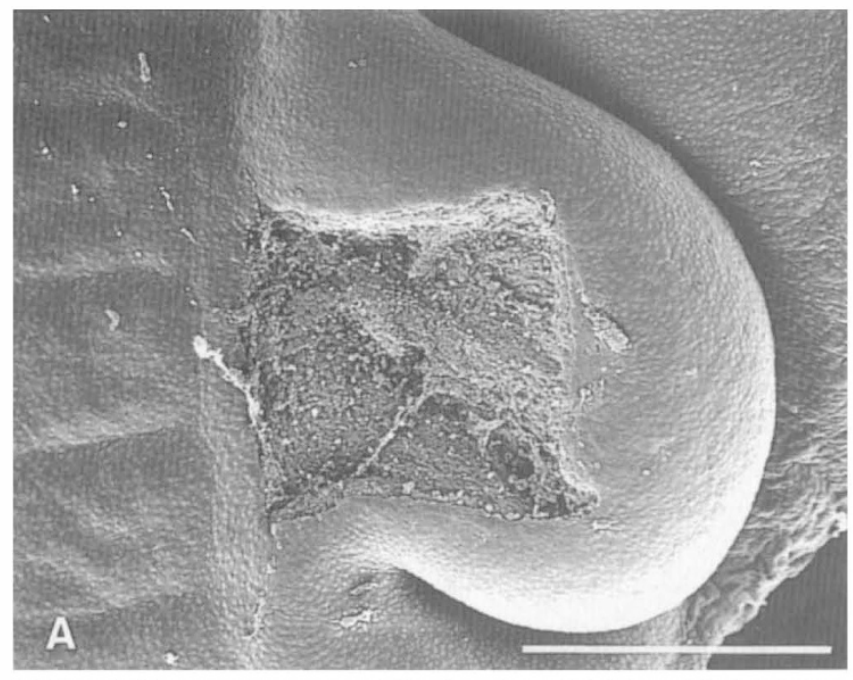

Fig. 1. Scanning electron micrographs of wound healing on the dorsum of the E4 chick wing bud. (A) Low magnification of the 0 hour wound, i.e. immediately after removal of a square of skin. (B) Six hours later the epidermal corners have rounded up and the wound has closed considerably. (C) A high-power detail of $(B)$ showing the healing epidermal wound edge as it sweeps in over the wound mesenchyme. (D) Eighteen hours after wounding the wound is almost closed. (E) High-power detail of the epidermal edge of an almost-closed 18 hour wound. Scale bars represent $(A),(B)$, and $(D), 500 \mu \mathrm{m} ;(C)$ and $(E) 50 \mu \mathrm{m}$.
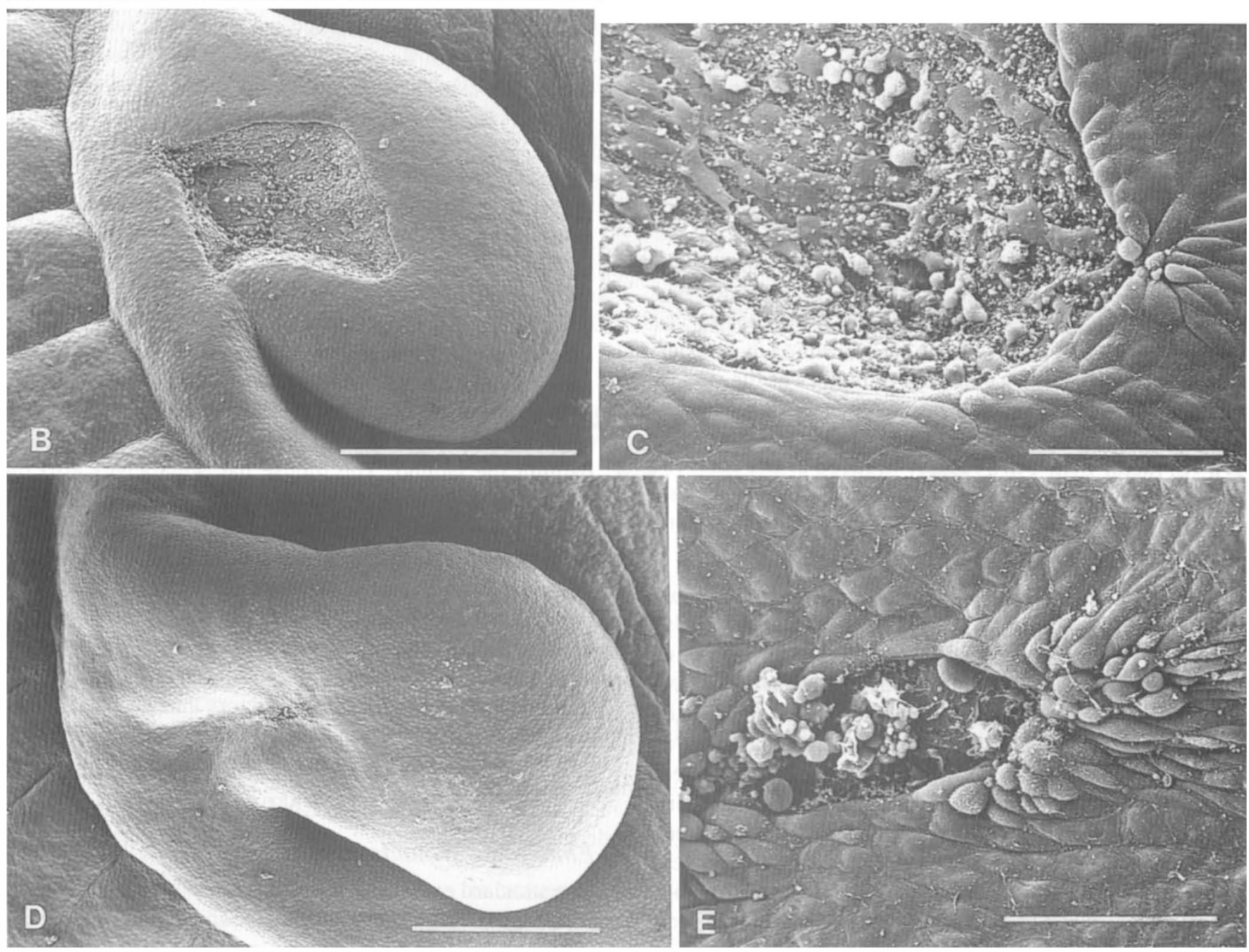

within 18-24 hours (Fig. 1D, E). To get an accurate picture of the timecourse of healing we have followed the process in living embryos in ovo, observing the wound margins of single lesions and recording their positions with camera lucida drawings made at various timepoints during the closure process. By measurement from these drawings we find that the embryonic wound front moves in at approximately $10-15 \mu \mathrm{m}$ per hour, with no observable initial lag phase, until the wound is closed. ${ }^{1}$

To follow mesenchymal movements, small groups of mesenchymal cells can be marked at various sites around the margin of the initially exposed connective tissue with a lipophilic marker dye, DiI. This reveals that wound closure is not entirely due to re-epithelialisation: while our data showed that the epidermal front does indeed sweep in over the marked mesenchymal cells, the area of mesenchyme bounded by the DiI dots is also reduced in size by the time the wound has closed, indicating that at least some of embryonic wound closure is due to mesenchymal or connective-tissue contraction. Thus, as in adult healing, 

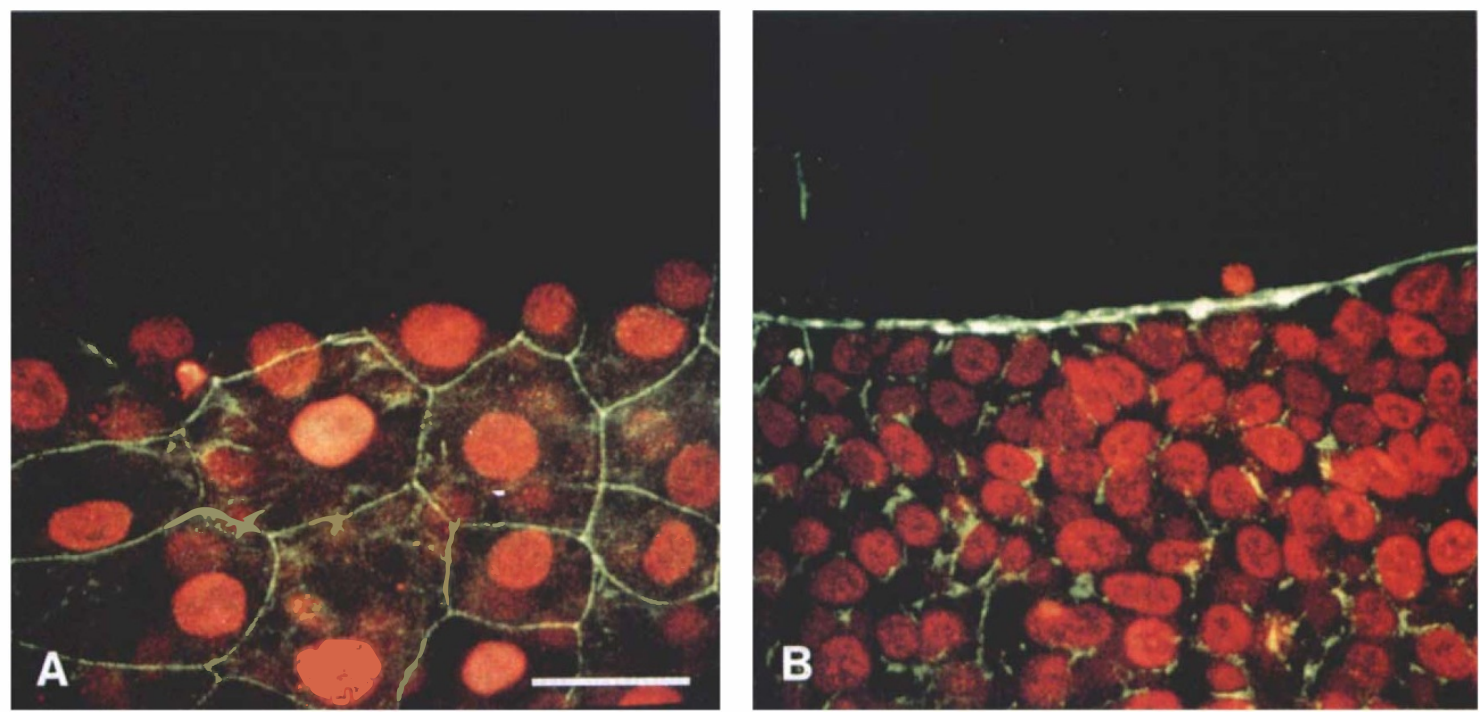

Fig. 2. Confocal laser scanning micrographs of the epidermal wound margin 1 hour after wounding the chick wing bud. FITC-phalloidin ${ }^{31}$ and 7AAD reveal filamentous actin (green) and nuclei (red) respectively. (A) Superficial section in the plane of the periderm showing pavement-like cells but no actin specialisation at the wound margin. (B) Deeper section in the plane of the cuboidal basal ectoderm cells, with a clear actin cable apparent in the front row at the leading edge. Scale bar represents $20 \mu \mathrm{m}$.

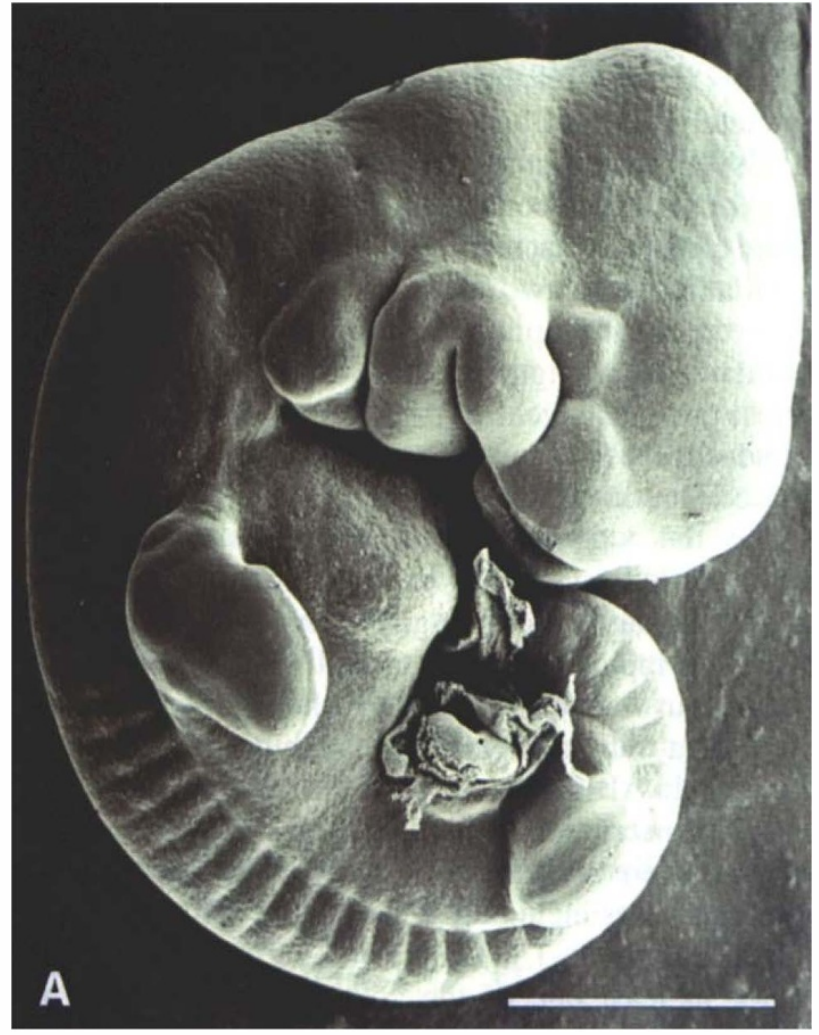

Fig. 3. Transcription factors and grow th factors expressed at the embryonic wound site. (A) Scanning electron micrograph of an E11.5 mouse embryo exposed just prior to hindlimb amputation. (B) Low-power view' of wholemount $c$-fos immunocytochemistry 1 hour after wounding showing $c$-fos protein (brown staining) in the epidermal cells of the wound margin (arrows) and to a lesser extent in the superficial mesenchymal cells. (C) High-power detail of $(B)$ showing $c$-fos protein in cells extending back as far as three or four rows from the woundedge. (D) Immunocytochemistry using an anti-TGF $\beta 1$ antibody on a section through a 3 hour mouse wound. TGF 1 protein (brown stain) is being secreted from epidermal wound edge cells into the wound mesenchyme (arrow). Scale bars represent: $(A), 1 \mathrm{~mm} ;(B), 200 \mu \mathrm{m} ;(C)$ and $(D), 50 \mu \mathrm{m}$.
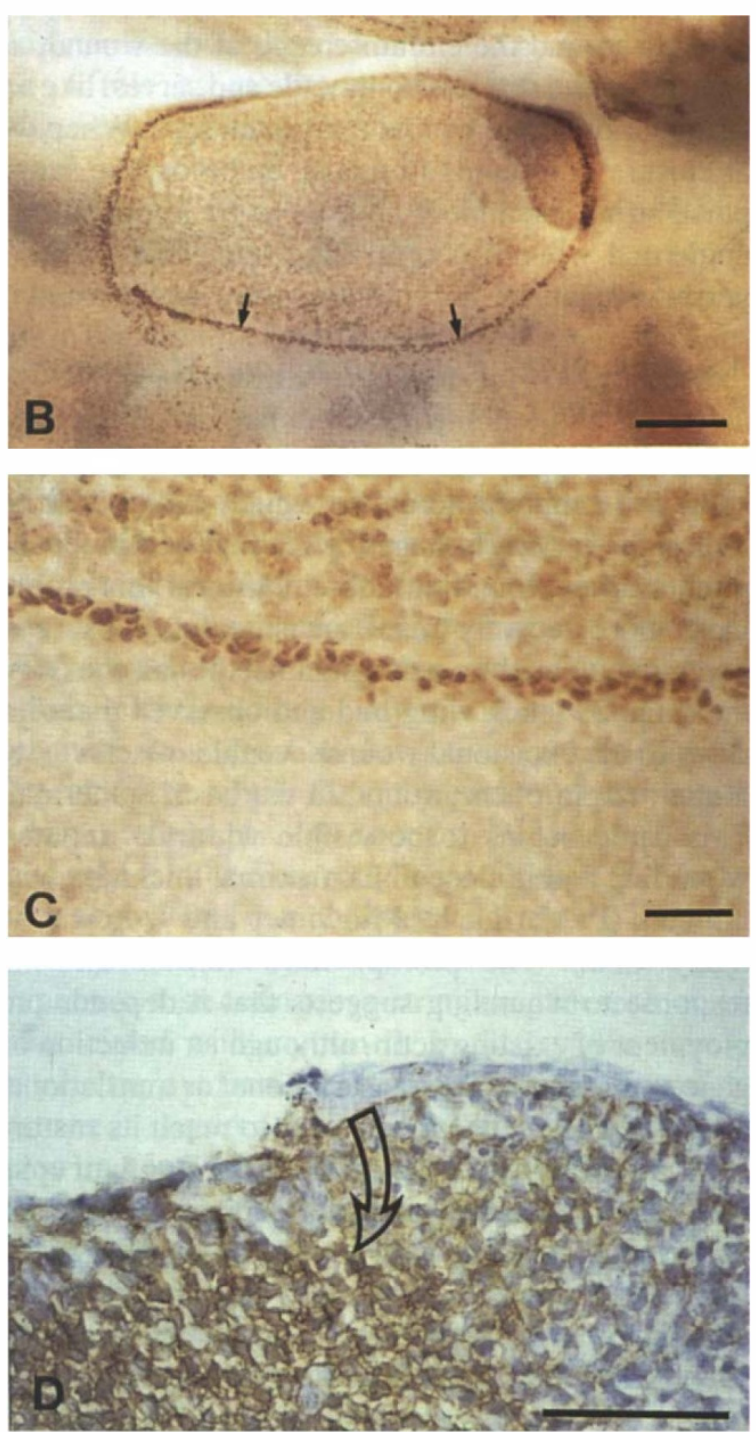
it appears that embryonic wound healing is driven by two tissue movements acting in concert: re-epithelialisation and connective-tissue contraction.

\section{Re-epithelialisation Appears to be Driven by Contraction of an Actin Purse-String in the Wound Marginal Epidermal Cells}

Our early studies in the chick focussed on the mechanisms of re-epithelialisation. Scanning electron microscopy and histological sections through the epidermal edges of a chick embryo wound reveal that the leading cells are not extending the tongue-like lamellipodia used by epidermal cells at an adult wound front to adhere to substrata and drag themselves forward. Rather, the embryonic wound fronts appeared smooth-edged. This lack of lamellipodial protrusions seems to rule out the conventional mechanism of cell motility - that of lamellipodial crawling (see, for example, Odland and Ross, ${ }^{8}$ Buck $\left.^{9}\right)-$ for closure of embryonic wounds. How then does the embryonic wound epidermis sweep forwards to cover over the wound? Using confocal laser scanning microscopy to view optical sections in the plane of the wound epithelium (Fig. 2) we found that a thick cable of filamentous actin is assembled in the basal marginal epidermal cells. This cable of actin extends around the circumference of the wound, and we have proposed that it is contractile and serves, like a pursestring, to draw the wound margin closed. ${ }^{1}$ When we look at closure of wounds in mouse embryos, the same actin purse-string machinery appears to be in operation at the epidermal wound margin, suggesting that this is a universal mechanism for wound closure in early embryos.

\section{Assembly of the Purse-String and Mechanism of Purse-String Closure}

Square excisional lesions of the type described above take some 5-10 minutes to create, which makes it difficult to look at the very early stages of healing (within seconds and minutes after wounding). To circumvent this problem we have more recently made incisional lesions (a simple linear cut created by a tungsten needle) on the dorsum of the stage 23 chick wing bud and observed them healing. As with the excisional wounds a cable of actin assembles at the margin of the wound in the basal epidermal cells. This cable begins to be visible within 2 minutes after wounding and is close to its maximal thickness within 10 minutes (P. Martin, K. Midwinter and J. Lewis, unpublished data). The prompt formation of the cable in response to wounding suggests that it depends on redeployment of existing actin, although an induction of actin gene expression at the transcriptional or translational level might be necessary for the cable to reach its mature size.

As an embryonic wound closes, the length of epidermal free edge around the perimeter decreases. This might be expected to correlate with a narrowing of the segment of perimeter formed by each cell, converting all marginal cells to an inward-pointing wedge shape. But in fact the average shape of the cells around the wound margin does not appear to change significantly as the wound closes, implying that wound closure must involve changes in cell-cell contacts, and not just changes in cell shape. We propose that tension in the actin cable drives cells to rearrange their contacts and lose their place in the marginal row, so that the number of cells in the marginal row gets progressively smaller as the wound closes. The incisional wounds show this phenomenon in an extreme form: they appear to heal by 'zipping-up' at their ends.

\section{c-fos is Rapidly Induced in the Cells at the Epidermal Wound Margin}

The role of connective-tissue contraction is best studied in excisional wounds. In the rodent embryo model (Fig. 3) our standard wound is a simple amputation of the hind limb bud at its base, which results in an ovoid lesion of very reproducible initial area and allows more accurate quantification of the extent of connective-tissue contraction than with our less easily standardised chick excisional wounds. Wounded mouse embryos are explanted into roller culture bottles where they grow and develop well in saline supplemented with $25 \%$ rat serum for up to 2 days. During this time they efficiently heal their limb bud wounds. The originally exposed, marked mesenchyme shrinks to approximately $50 \%$ of its initial area during the 24 hours it takes for the limb amputation wound to heal completely (J. McCluskey and P. Martin, unpublished data), suggesting that re-epithelialisation and connectivetissue contraction contribute about equally (50:50) to wound closure. What molecular signals might be involved in initiating these two crucial healing movements? We have searched for rapidly induced molecular events at the wound edge that might provide a trigger. We find that the nuclear proto-oncogene c-fos is switched on in epidermal wound edge cells, and to a lesser extent in superficial exposed wound mesenchyme cells, within 15 minutes of making the wound. ${ }^{9 a}$ Whilst the c-fos induction we see - revealed using a polyclonal antibody raised against the N-terminus of c-fos (gift from Dr Gerard Evan, ICRF) - is rapid, it is also transient with no c-fos protein to be seen in wound edge cells by 4 hours after wounding.

c-fos is a transcription factor that binds co-operatively with c-jun to AP-1 regulatory sites in the genome and thus controls transcription. Among the known downstream target genes there are several of likely importance in tissue repair processes including genes coding for transforming growth factor beta-1 (TGF $\beta 1$ ) and various other growth factors, at least one of the collagens, collagenase and stromelysin. ${ }^{10-12}$ c-fos has also been implicated in the initiation of cell proliferation in tissue culture studies (reviewed in Mehmet and Rozengurt ${ }^{13}$ ) and so it would be interesting to investigate whether c-fos induction at the wound edge plays any role in triggering upregulation of cell division to supply a pool of cells to help fill the defect.

\section{c-fos May Upregulate TGF $\beta 1$ Which in Turn May Trigger Connective-Tissue Contraction}

We have looked in detail at expression of one of the AP1regulated genes, the growth factor TGF $\beta 1$, at the embryo- 
nic wound site. We find that precisely the same population of cells that had previously expressed c-fos subsequently upregulates TGF $\beta 1$. TGF $\beta 1$ mRNA becomes evident in the epidermal wound front cells and in the superficial wound mesenchyme cells from about 1 hour after wounding, and using a polyclonal antibody recognising extracellular TGF $\beta 1$ (gift from Kathy Flanders, Bethesda), we find that the expressing cells secrete protein into the adjacent wound mesenchyme. ${ }^{14}$ This protein is then fairly rapidly cleared so that by 18 hours after wounding levels are back to background. Thus induced TGF $\beta 1$ is present in the wound mesenchyme throughout the period of wound closure, but not after. Simple tissue culture models of connective-tissue contraction reveal that TGF $\beta$ will significantly enhance the contractile capacity of fibroblasts embedded in a collagen gel, ${ }^{15}$ and recently it has been shown that TGF $\beta 1$, and not other growth factors, can signal conversion of fibroblasts into contractile myofibroblasts in vitro and in vivo. ${ }^{16}$ For these reasons we have speculated that TGF $\beta 1$ induced at the embryonic wound site might be responsible for triggering contraction of the wound mesenchyme. ${ }^{14}$

\section{Neither Platelets nor Macrophages Are Present at the Embryonic Wound Site as Supplementary Sources of Growth Factors}

Adult wounds are supplied with abundant growth factors brought in by transitory platelet and macrophage cell populations (reviewed in Martin et al. ${ }^{17}$ ). This is not the case in the embryo, where resident epidermal and mesenchymal cells at the wound site, as described above, appear to be the only source of growth factors. Megakaryocytes - the progenitors of platelets - do not even begin to differentiate in the fetal liver until about E13 $\left(\operatorname{Rugh}^{18}\right), 2$ days after we make our wounds. Moreover, while macrophages first make their appearance in the mouse embryo as early as E10 (Morris et al. ${ }^{19}$ ), we have recently shown, using the macrophage-specific monoclonal antibody $\mathrm{F} 4 / 80$, that macrophages, although detectable elsewhere in the embryo, are not recruited to wounds in the E11.5 mouse embryo at any stage during their very efficient healing process. ${ }^{19 a}$ One possible explanation for this lack of a macrophage invasion of embryonic excisional wounds is that relatively little cell death occurs at the wound site. ${ }^{20}$

\section{DISCUSSION AND NEXT STEPS}

Because the embryonic skin is structurally so much simpler than its adult counterpart and because an embryonic wound is not obscured by a scab and heals without the complications of an inflammatory response, it is easier in the embryo than it is in the adult to investigate the cellular machinery of wound closure and its control. But there is still a lot we do not know.

\section{What Signals an Actin Purse-String to Assemble at the Wound Margin?}

We have some speculations, though very little evidence, as to what might signal the initial formation and subsequent contraction of an actin cable at the embryonic wound margin. A cut creates a free epidermal edge and disrupts the pattern of tensions within the originally intact epidermal sheet. For the cells at the cut edge the component of tension acting at right angles to the cut is lost, leaving the major axis of tension parallel to the wound margin. From the tissue culture studies of Kolega ${ }^{21}$ we know that such oriented lines of tension are sufficient to promote actin filament alignment within single epidermal cells and, hence, by extrapolation to the in vivo wound situation, could drive formation of an actin cable at the epidermal junction. The act of wounding may also cause an influx of calcium ions, triggering contraction of the cable. Evidence that a calcium influx might be necessary at some stage during embryonic wound closure comes from Stanisstreet $^{22}$ who has shown that removing calcium from the medium in which Xenopus embryos are wounded completely blocks wound closure.

Recent studies have shown that the small GTP-binding protein rho mediates rapid assembly of stress fibres in response to growth factors in tissue culture fibroblasts. ${ }^{23}$ The timescale of this response is similar to that of the assembly of actin cable we see at wound edges. We are keen to determine whether rho or related proteins might be playing a role as mediators of stretch-induced actin assembly in our system.

\section{What Vertebrate Morphogenetic Movements Might Utilise a Contractile Actin Purse-String?}

Actin purse-strings are probably not unique to healing wounds in the embryo, but may be used by a variety of epithelial cells as part of the machinery to coordinate their activities during normal development. Two recent papers on other systems support this view and suggest that contractile actin purse-strings may be a common feature of epithelial behaviour. One, by Bement et al. ${ }^{24}$ describes the healing of small wounds in monolayers of a gut epithelial cell line in culture and describes formation of an actin cable very similar to the one we have seen. These authors show that the cable contains myosin II, as well as actin, strengthening the suggestion that active contraction of the cable provides the motile force for epidermal movement. The other recent paper, by Young et $a .^{25}$ describes the morphogenetic movement of dorsal closure in Drosophila, whereby the dorsal epidermis closes over the amnioserosa of the embryo. In the cells at the leading edge of the epidermis, an actin purse-string is again seen, and is again associated with myosin II. In this system there is strong genetic evidence that active contraction of the purse-string is required for closure, since closure fails in the zipper mutant, which lacks zygotic myosin II.

Free edges of the sort seen at an epidermal wound edge are rare in development, but it seems likely that modified versions of the actin purse-string might drive a number of the slidings and foldings of epithelial sheets that shape the embryo. Certainly, there good evidence that closure of the neural tube involves microfilament contraction. ${ }^{26}$ Other 
candidates for morphogenetic movements dependent on a purse-string are epiboly in fish, closure of the blastopore lip in the frog, otic vesicle invagination and eyelid closure.

\section{Testing the Role of Induced Immediate-Early Genes and Growth Factors at the Embryonic Wound Site}

While the gene inductions we see at an embryonic wound edge suggest that c-fos and TGF $\beta 1$ may have a functional role in directing the observed connective-tissue contraction, we have no firm proof that this is the case. Experiments with transgenic knockout mice may provide a test. There are already a number of lines of mouse that are null for the two genes we have shown to be upregulated at the wound site: $c-f o s^{27,28}$ and TGF $\beta 1 .^{29,30}$ Both c-fos and TGF $\beta 1$ knockout mice appear viable (at least the majority of embryos do) for the duration of gestation and are therefore suitable for investigation using our embryonic wound model.

Work described in this review was funded by the ICRF, the MRC, the Anatomical Society of Great Britain and Ireland and the Phoenix Appeal. Thanks are also due to Dr Rosemary Akhurst's group for permission to show our shared TGF $\beta$ data.

Key words: Embryo, Wound healing, Actin, c-fos, $\operatorname{TgF} \beta$, Macrophage.

\section{REFERENCES}

1. Martin P, Lewis J. Actin cables and epidermal movement in embryonic wound healing. Nature 1992;360:179-83.

2. Radice GP. The spreading of epithelial cells during wound closure in Xenopus larvae. Dev Biol 1980;76:26-46.

3. Stanisstreet M, Wakely J, England MA. Scanning electron microscopy of wound healing in Xenopus and chicken embryos. J Embryol Exp Morphol 1980;59:341-53.

4. Thevenet A. Wound healing of the integument of the 5 day chick embryo. Arch Anat Microsc Morphol Exp 1981; 70:227-44.

5. Whitby DJ, Ferguson MWJ. The extracellular matrix of lip wounds in fetal, neonatal and adult mice. Development 1991;112:651-68.

6. Whitby DJ, Ferguson MWJ. Immunohistochemical localisation of growth factors in fetal wound healing. Dev Biol 1991;147:207-15.

7. Hamburger V, Hamilton HL. A series of normal stages in the development of the chick embryo. J Morphol 1951;88: 49-92.

8. Odland G, Ross R. Human wound repair. I. Epidermal regeneration. J Cell Biol 1968;39:1135-51.

9. Buck RC. Cell migration in repair of mouse corneal epithelium. Invest Ophthalmol Vis Sci 1979;18:767-84.

9a. Martin P, Nobes CD. An early molecular component of the wound healing response in rat embryos: induction of c-fos protein in cells at the epidermal wound margin. Mcch Dev 1992;38:209-16.

10. Gutman A, Wasylyk B. Nuclear targets for transcription regulation by oncogenes. Trends Genet 1991;7:49-54.

11. Roberts AB, Kim SJ, Kondaiah P, Jakowlew SB, Denhez F, Glick $\mathrm{AB}$ et al. Transcriptional control of expression of the TGFßs. Ann NY Acad Sci 1991;593:43-90.

12. Schonthal A, Herrlich P, Rahmsdorf HJ, Ponta H. Requirement for fos gene expression in transcriptional activation of collagenase by other oncogenes and phorbol esters. Cell 1988;54:325-34.
13. Mehmet H, Rozengurt E. Regulation of c-fos expression in Swiss 3T3 cells: an interplay of multiple signal transduction pathways. Br Med Bull 1991;47:76-86.

14. Martin P, Dickson MC, Millan FA, Akhurst RJ. Rapid induction and clearing of TGF $\beta 1$ is an early response to wounding in the mouse embryo. Dev Genet 1993; 14:225-38.

15. Montesano R, Orci L. Transforming growth factor $\beta$ stimulates collagen matrix contraction by fibroblasts: implications for wound healing. Proc Natl Acad Sci USA 1988;85:4894-7.

16. Desmouliere A, Geinoz A, Gabbiani F, Gabbiani G. Transforming growth factor- $\beta 1$ induces $\alpha$-smooth muscle actin expression in granulation tissue myofibroblasts and in quiescent and growing cultured fibroblasts. J Cell Biol 1993; 122:103-11.

17. Martin P, Hopkinson-Woolley J, McCluskey J. Growth factors and cutaneous wound repair. Prog Growth Factor Res $1992 ; 4: 25-44$.

18. Rugh R. The mouse: its reproduction and development. Oxford: Oxford University Press, 1990.

19. Morris L, Graham CF, Gordon S. Macrophages in haemopoietic and other tissues of the developing mouse detected by the monoclonal antibody F4/8;. Development 1991; 112:517-26.

19a. Hopkinson-Woolley J, Hughes DA, Gordon S, Martin P. Macrophage recruitment during limb development and wound healing in the embryonic and foetal mouse. J Cell Sci (in press).

20. McCluskey J, Hopkinson-Woolley J, Luke B, Martin P. A study of wound healing in the E11.5 mouse embryo by light and electron microscopy. Tissue Cell 1993;25:173-81.

21. Kolega J. Effects of mechanical tension on protrusive activity and microfilament and intermediate filament organisation in an epidermal epithelium moving in culture. $\mathbf{J}$ Cell Biol 1986;102:1400-11.

22. Stanisstreet M. Calcium and wound healing in Xenopus early embryos. J Embryol Exp Morphol 1982;67:195-205.

23. Ridley AJ, Hall A. The small GTP-binding protein rho regulates the assembly of focal adhesions and actin stress fibres in response to growth factors. Cell 1992;70:389-99.

24. Bement WM, Forscher P, Mooseker MS. A novel cytoskeletal structure involved in purse-string wound closure and cell polarity maintenance. J Cell Biol 1993;121:565-78.

25. Young PE, Richman AM, Ketchum AS, Kiehart DP. Morphogenesis in Drosophila requires non-muscle myosin heavy chain function. Genes Dev 1993;7:29-41.

26. Morriss-Kay G, Tuckett F. The role of microfilaments in cranial neurulation in rat embryos: effects of short term exposure to cytochalasin D. J Embryol Exp Morphol 1985;88: 333-48.

27. Johnson RS, Spiegelman BM, Papaioannou V. Pleiotrophic effects of a null mutation in the c-fos proto-oncogene. Cell 1992;71:577-86.

28. Wang Z-Q, Ovitt C, Grigoriadis AE, Mohle-Stenlein U, Ruther U, Wagner EF. Bone and haematopoietic defects in mice lacking c-fos. Nature 1992;360:741-5.

29. Kulkarni AB, Huh C-G, Becker D, Geiser A, Lyght M, Flanders $\mathrm{KC}$ et al. Transforming growth factor $\beta 1$ null mutation in mice causes excessive inflammatory response and early death. Proc Natl Acad Sci USA 1993;90:770-4

30. Shull MM, Ormsby I, Kier AB, Pawlowski S, Diebold RJ, Yin $\mathrm{M}$ et al. Targeted disruption of the mouse transforming growth factor- $\beta 1$ gene results in multifocal inflammatory disease. Nature 1992;359:693-9.

31. Wulf E, Deboben A, Bautz FA, Faulstich H, Wieland T. Fluorescent phallotoxin, a tool for the visualisation of cellular actin. Proc Natl Acad Sci USA 1979;76:4498-502. 